\title{
Effect of syllabic neighbourhood as a function of syllabic neighbour length
}

\author{
Fabienne Chetail • Stéphanie Mathey
}

Published online: 2 August 2011

(C) Psychonomic Society, Inc. 2011

\begin{abstract}
The concept of syllabic neighbours (words sharing the same first syllable) is central in the interpretive framework of syllabic effects in visual word recognition. However, the definition of this concept remains surprisingly vague, so it is not clear whether or not syllabic competition is driven by words of similar syllabic length. The present study aimed to refine the definition by investigating the effect of higher-frequency syllabic neighbourhood as a function of syllabic neighbour length (similar syllabic length to the target words vs. any syllabic length). In both standard and go/no-go lexical decision tasks, the data showed that increasing the number of higher-frequency syllabic neighbours had an influence only when this number was computed from words of the same syllabic length as the target. Syllabic neighbours may therefore be considered as words sharing the first syllable and the total number of syllables with the target. Implications for accounts of syllable neighbourhood effects are discussed.
\end{abstract}

Keywords Visual word recognition · Syllable · Syllabic neighbours $\cdot$ Lexical competition

Electronic supplementary material The online version of this article (doi:10.3758/s13423-011-0138-1) contains supplementary material, which is available to authorized users.

F. Chetail $(\bowtie)$

Laboratoire Cognition Langage et Développement (LCLD), Université Libre de Bruxelles,

Av.F. Roosevelt, 50,

CP 191, 1050 Brussels, Belgium

e-mail: fchetail@ulb.ac.be

F. Chetail $\cdot$ S. Mathey

Université Bordeaux Segalen,

Bordeaux, France
The syllable is a major intralexical unit that has received much attention in polysyllabic word processing. Numerous studies have led to the proposal that syllables might be important phonological units mediating lexical access. Specifically, the role of syllables in visual word recognition has been widely investigated by means of the syllable frequency effect. Initially, the processing of bisyllabic words with high-frequency syllables was compared to that of bisyllabic words with low-frequency syllables (Carreiras, Álvarez, \& de Vega, 1993). In the lexical decision task (LDT), an inhibitory effect was reported, high-frequency-syllable words being recognized more slowly than low-frequencysyllable words. This effect was accounted for in terms of syllabic neighbourhood. The more frequent a syllable, the more it is shared by words, referred to as syllabic neighbours. During visual word recognition, these neighbours are activated and compete with the target, thus slowing down its processing. Competition is stronger when there are numerous syllabic neighbours - that is, when the target contains a highfrequency rather than a low-frequency syllable.

The inhibitory effect of syllable frequency has been widely replicated in follow-up studies, especially when the frequency of the first syllable in words was manipulated (e.g., Álvarez, Carreiras, \& de Vega, 2000; Chetail \& Mathey, 2009; Conrad \& Jacobs, 2004; Conrad, Grainger, \& Jacobs, 2007; Perea \& Carreiras, 1998; Stenneken, Conrad, Hutzler, Braun, \& Jacobs, 2005). In line with the account proposed, studies manipulating the number of higher-frequency syllabic neighbours (HFSNs) also reported inhibitory effects (e.g., Mathey \& Zagar, 2002; Mathey, Zagar, Doignon, \& Seigneuric, 2006; Perea \& Carreiras, 1998), so that this variable was considered as the factor responsible for the inhibitory nature of the syllable frequency effect (see Perea \& Carreiras, 1998). On the contrary, Conrad, Carreiras, and Jacobs (2008) argued that 
the syllable frequency per se would drive the competition process, given that they reported an inhibitory effect when they manipulated syllable frequency while controlling for the number of HFSNs. These two patterns of results are not inconsistent, inasmuch as syllable frequency and number of syllabic neighbours are naturally correlated.

In a modelling perspective, these effects of syllable frequency and syllabic neighbourhood have been used as strong arguments to modify the architecture of interactive activation models (McClelland \& Rumelhart, 1981) by including a syllabic representation level between the letter and word representation levels (e.g., Conrad, Carreiras, Tamm, \& Jacobs, 2009; Mathey et al., 2006). Especially, a computational version of the interactive activation model that integrated proposals from Conrad et al. (2009) successfully simulated syllable frequency and neighbourhood effects (Conrad, Tamm, Carreiras, \& Jacobs, 2010). However, although the concept of syllabic neighbourhood is crucial in the interpretation of syllabic effects, its definition is rather vague. Initially, the notion of syllabic neighbourhood was proposed in parallel to that of orthographic neighbourhood, with orthographic neighbours being "words that can be produced by changing just one of the letters in the string to another letter, preserving letter position" (Coltheart, Davelaar, Jonasson, \& Besner, 1977, p. 544; see also Davis, Perea, \& Acha, 2009; Yarkoni, Balota, \& Yap, 2008, for a revised definition). Attempting to define the notion of syllabic neighbourhood, Perea and Carreiras (1998) proposed that syllabic neighbours were "words that share a syllable in the same position with the target"; a footnote specified that "In the case of bisyllabic words, two words are syllabic neighbours when they share the first or the second syllable, although the first syllable is probably the most important" (p. 135 for both). This implies that two words are syllabic neighbours when they share a syllable at a given position (especially in the first position) and when they have the same number of syllables. Surprisingly, however, subsequent studies on syllabic neighbourhood did not refer to the latter point, so it is not clear whether competition between syllabic neighbours is driven by words of equal syllabic length (e.g., caler and cadran in French) or by words that can have different syllabic lengths (e.g., caler and canalisation). For example, Carreiras and Perea (2002) stated that syllabic neighbours are "words that share a syllable with the target word, especially the first syllable" (p. 1228). Along the same lines, Mathey et al. (2006) reiterated that syllabic neighbours are "words sharing the same first syllables" (p. 374).

With regard to how measures of syllabic frequency and neighbourhood are computed, some studies (using the LDT) have used measures computed from words with identical syllabic length (e.g., Conrad et al., 2007, 2009; Mathey \& Zagar, 2002; Mathey et al., 2006), others used measures computed from all words, independently of syllabic length (e.g., Álvarez et al., 2000; Carreiras et al., 1993; Conrad \& Jacobs, 2004), and others still did not indicate which computation was used (e.g., Álvarez, Carreiras, \& Taft, 2001; Chetail \& Mathey, 2009; Stenneken et al., 2005). The fact that syllabic neighbourhood and syllable frequency have been computed while either taking or not taking into account the number of syllables of the neighbours does not call into question the previous findings, since these two kinds of measure are highly correlated. However, distinguishing the roles of different types of competitors (syllabic neighbours sharing the same number of syllables with the target vs. syllabic neighbours being syllabically longer or shorter than the target) is a crucial issue inasmuch as understanding the processes of competition between syllabic neighbours requires defining which cohort of lexical competitors is activated during lexical access. Additionally, from a methodological perspective, this should clarify how to count syllabic neighbours when designing psycholinguistic experiments (see Davis et al., 2009, for a similar argument concerning orthographic neighbourhood).

The aim of the present study was therefore to investigate whether inhibitory syllabic effects are driven by a restricted cohort of competitors, where words share a given syllable plus the same number of syllables, or by a wider cohort, including competitors of any syllabic length. To investigate this issue, two methods of computing the number of HFSNs of bisyllabic target words were cross-factorially manipulated in the present study. Target words had either a high or a low number of HFSNs, as computed from words sharing the first syllable and the same number of syllables (i.e., two-syllable-long words). Target words could also have either a high or a low number of HFSNs, as computed from all words sharing the first syllable (i.e., two- to eight-syllable-long words). Manipulating orthogonally these two methods of computing the number of HFSN makes it possible to test which kinds of syllabic neighbours are responsible for syllabic competition effects during lexical access.

\section{Experiment 1}

Method

Participants A group of 45 volunteer students participated in this experiment. They were all native French speakers and reported having corrected-to-normal vision.

Material A total of 60 bisyllabic words of low frequency were selected from the French lexical database Lexique (New, Pallier, Brysbaert, \& Ferrand, 2004). Four experimental conditions were created according to the orthogonal combination of two factors: Number of HFSNs Computed 
From Words With the Same Number of Syllables (HFSNS) and Number of HFSNs Computed From All Words, irrespective of syllabic length (HFSNA). These syllabic measures were computed from the phonological forms of words. Of the words, 30 had a high number of HFSNS, while the remaining 30 had a lower number of HFSNS. In each half, 15 words had a high number of HFSNA and 15 had a lower number of HFSNA. Words were controlled for a set of variables known to influence the latencies of written word recognition (see Table 1). ${ }^{1}$ None of the stimuli had any higher-frequency orthographic neighbours, and most of the words had a CV first syllable (77\%); the other types of syllabic structures (CVC, CVV, CCV, VC, and VV) were equally distributed in the four conditions. Twenty word fillers were added to increase the number of trials, and 80 orthographically legal and pronounceable nonwords were added according to the requirements of the task. The stimuli are available in the online supplementary materials.

Procedure Participants performed a standard LDT using the DMDX software (Forster \& Forster, 2003). Each trial began by the presentation of a fixation point for $500 \mathrm{~ms}$ at the centre of the screen, which was replaced by a lowercase target item. The target remained on the screen until the participants responded or until 2,500 ms had elapsed. Participants had to decide as quickly and accurately as possible whether or not the target was a French word by pressing one of two buttons on a keyboard. Visual feedback was provided when they failed to respond or when 2,500 ms had elapsed. Reaction times (in milliseconds) were measured from target onset until the participant responded. All participants performed 12 practice trials before receiving the 160 experimental trials in a different random orders.

\section{Results and discussion}

The mean correct reaction times and mean error rates averaged over participants for words are presented in Table 2. Reaction times shorter than $300 \mathrm{~ms}$ or longer than $1,500 \mathrm{~ms}$ were removed $(0.68 \%$ of the data). One word was excluded from the analyses because of a high error rate (disette, 57\%). The data were submitted to separate analyses of variance on the participant means $\left(F_{1}\right)$ and on the item means $\left(F_{2}\right)$, with Number of HFSNS (high, low) and Number of HFSNA (high, low) as the main factors.

The analysis on reaction times showed a significant effect of number of HFSNS, $F_{1}(1,44)=60.42, p<.001$, and $F_{2}(1$,

\footnotetext{
${ }^{1}$ Words were not controlled a priori for additional variables such as age of acquisition or imageability (but see Conrad et al., 2008, for a discussion on imageability). A posteriori, it was checked that syllabic effects were not confounded with morphemic variables (see also Álvarez et al., 2001).
}

$55)=5.65, p=.02$. Words with a high number of HFSNS were recognized more slowly $(688 \mathrm{~ms})$ than words with a low number of HFSNS (656 ms). Neither the main effect of HFSNA nor the interaction effect was significant: respectively, $F_{1}(1,44)=1.38, p=.25, F_{2}<1$, and $F_{1}, F_{2}<1$.

In the error analysis, the effect of number of HFSNS was significant, $F_{1}(1,44)=32,19, p<.001$, and $F_{2}(1,55)=$ $6.01, p=.02$. For both the number of HFSNA and the interaction, the effect was significant in the participants analysis only, $F_{1}(1,44)=6.04, p=.02, F_{2}(1,55)=1.29$, $p=.26$, and $F_{1}(1,44)=9.69, p=.003, F_{2}(1,55)=1.81$, $p=.18$, respectively. ${ }^{2}$

When the number of HFSNS and the number of HFSNA were cross-factorially manipulated, the data showed that only the number of HFSNS yielded an inhibitory effect on reaction times and error rates. This suggests that the syllabic neighbours involved in lexical competition were words sharing a first syllable and the total number of syllables with the target. Before discussing these data further, we conducted a second experiment to test the generalization of the findings with a go/no-go procedure that would enable us to collect more accurate responding and faster reaction times and that would require fewer processing resources than the yes/no procedure (see Perea, Rosa, \& Gómez, 2002).

\section{Experiment 2}

\section{Method}

Participants A group of 44 students participated in this experiment for course credit. They were all native French speakers and reported having corrected-to-normal vision. None of them had participated in the previous experiment.

Materials The same materials were used as in Experiment 1 .

Procedure The procedure was the same as in Experiment 1, except that the participants performed a go/no-go LDT. They were instructed to press a response key with their dominant hand when the letter string was a French word, and to refrain from responding when it was not.

\section{Results}

The mean correct reaction times and mean error rates averaged over participants for words are presented in

\footnotetext{
${ }^{2}$ The results for error rates were highly similar through arcsine transformation, both in Experiments 1 and 2 (see Jaeger, 2008).
} 
Table 1 Characteristics of target words

HFSNS, higher-frequency syllabic neighbours computed from bisyllabic words only; HFSNA, higher-frequency syllabic neighbours computed from words of any syllabic length; SFA, syllable frequency computed from words of any syllabic length; SFS, syllable frequency computed from bisyllabic words only; SNA, syllabic neighbours computed from words of any syllabic length; SNS, syllabic neighbours computed from bisyllabic words only. There were no significant differences across conditions for the controlled variables (one-way ANOVAs and Tukey's HSD post hoc tests, all $p s>.10) .{ }^{1}$ Collected for 10 participants on a five-point Likert scale

\begin{tabular}{|c|c|c|c|c|}
\hline & \multicolumn{4}{|c|}{ Number of HFSNS } \\
\hline & \multicolumn{2}{|l|}{ High } & \multicolumn{2}{|l|}{ Low } \\
\hline Number of HFSNA & High & Low & High & Low \\
\hline \multirow[t]{2}{*}{ Examples } & microbe & vidange & sucrer & junior \\
\hline & \multicolumn{4}{|c|}{ Manipulated Variables } \\
\hline Number of HFSNS [range] & $41[33-48]$ & 37 [31-49] & 20 [9-29] & 19 [11-26] \\
\hline \multirow[t]{2}{*}{ Number of HFSNA [range] } & $77[60-94]$ & $51[41-58]$ & $81[59-112]$ & $42[25-53]$ \\
\hline & \multicolumn{4}{|c|}{ Covarying Variables } \\
\hline SFA (1st syllable) & 3,740 & 3,204 & 1,766 & 1,300 \\
\hline SFS (1st syllable) & 1,411 & 855 & 529 & 634 \\
\hline Number of SNA (1st syllable) & 431 & 238 & 482 & 215 \\
\hline \multirow[t]{2}{*}{ Number of SNS (1st syllable) } & 126 & 107 & 56 & 70 \\
\hline & \multicolumn{4}{|c|}{ Controlled Variables } \\
\hline Lexical frequency (books) & 3.42 & 2.46 & 3.82 & 3.13 \\
\hline Lexical frequency (films) & 4.16 & 3.22 & 10.87 & 3.24 \\
\hline Subjective frequency ${ }^{1}$ & 2.74 & 2.34 & 3.09 & 2.78 \\
\hline Orthographic neighbourhood & 0.67 & 1.00 & 1.00 & 0.60 \\
\hline Phonological neighbourhood & 4.87 & 4.53 & 3.27 & 4.67 \\
\hline Number of letters & 6.73 & 6.93 & 6.73 & 6.93 \\
\hline Summed bigram frequency & 2,091 & 2,223 & 2,030 & 2,008 \\
\hline Frequency of the first bigram & 539 & 482 & 577 & 617 \\
\hline SFA (2nd syllable) & 82 & 77 & 181 & 192 \\
\hline SFS (2nd syllable) & 65 & 40 & 78 & 140 \\
\hline Number of SNA (2nd syllable) & 22 & 29 & 60 & 52 \\
\hline Number of SNS (2nd syllable) & 11 & 11 & 12 & 24 \\
\hline
\end{tabular}

Table 3. Reaction times shorter than $300 \mathrm{~ms}$ or longer than $1,500 \mathrm{~ms}$ were removed $(0.99 \%$ of the data). Three words were excluded from the analyses because of high error rates (disette, 32\%; civet, 36\%; and rocade, 59\%). The data were submitted to separate analyses of variance on the participant means $\left(F_{1}\right)$ and on the item means $\left(F_{2}\right)$ with Number of HFSNS (high, low) and Number of HFSNA (high, low) as main factors.

The analysis on reaction times showed a significant effect of number of HFSNS, $F_{1}(1,43)=27.40, p<.001$, and $F_{2}(1,53)=4.80, p=.03$. Words with a high number of HFSNS were recognized more slowly $(688 \mathrm{~ms})$ than words

Table 2 Mean reaction times (in milliseconds) and error rates (parentheses) for target words in Experiment 1

\begin{tabular}{llll}
\hline & & \multicolumn{2}{l}{ Number of HFSNA } \\
\cline { 3 - 4 } & & High & Low \\
\hline Number of HFSNS & High & $689(7.7)$ & $686(3.7)$ \\
& Low & $659(1.6)$ & $652(1.9)$ \\
\hline
\end{tabular}

HFSNA, higher-frequency syllabic neighbours computed from words of any syllabic length; HFSNS, higher-frequency syllabic neighbours computed from bisyllabic words only with a low number of HFSNS (656 ms). Neither the main effect of HFSNA nor the interaction effect was significant: respectively, $F_{1}(1,43)=1.01, p=.32, F_{2}<1$, and $F_{1}(1,43)=$ $1.28, p=.27, F_{2}<1$.

In the error analysis, the effect of number of HFSNS was significant, $F_{1}(1,43)=10.90, p=.002$, and $F_{2}(1,53)=$ $3.81, p=.056$, but neither the effect of HFSNS, $F_{1}, F_{2}<1$, nor the interaction effect, $F_{1}, F_{2}<1$, was.

The results of this second experiment were very similar to those found in Experiment 1: When the number of HFSNA was controlled for, an inhibitory effect of number of HFSNS was obtained, while no effect was found in the reverse situation.

\section{General discussion}

The aim of the present study was to provide a more precise definition of syllabic neighbourhood than has been proposed to date. To do so, the inhibitory syllabic neighbourhood effect was investigated for a set of words while manipulating orthogonally the number of HFSNs computed from words of identical syllabic length (HFSNS) and from words of any syllabic length (HFSNA). 
Table 3 Mean reaction times (in milliseconds) and error rates (parentheses) for target words in Experiment 2

\begin{tabular}{llll}
\hline & & \multicolumn{2}{l}{ Number of HFSNA } \\
\cline { 3 - 4 } & & High & Low \\
\hline Number of HFSNS & High & $666(1.9)$ & $652(2.1)$ \\
& Low & $621(0.6)$ & $623(0.6)$
\end{tabular}

HFSNA, higher-frequency syllabic neighbours computed from words of any syllabic length; HFSNS, higher-frequency syllabic neighbours computed from bisyllabic words only

In two experiments, we replicated the inhibitory effect of HFSN (e.g., Mathey \& Zagar, 2002; Mathey et al., 2006; Perea \& Carreiras, 1998) in both standard and go/no-go LDTs, thus providing new support for the hypothesis of competition between syllabic neighbours during lexical access. Additionally, we showed that varying task requirements did not influence the emergence of syllable effects (see also Mathey et al., 2006). The fact that the same effects were observed with the go/no-go procedure and the standard yes/no LDT task suggests that the effect of HFSN number did not emerge at the stage of response selection, but at the lexical selection and/or decision stages (see Perea et al., 2002). More importantly, obtaining a syllabic neighbourhood effect only when manipulating the number of HFSNs computed from words sharing the same number of syllables with the target word (i.e., on bisyllabic words) made it possible to refine to some extent the definition of syllabic neighbourhood. The syllabic neighbours that noticeably participate in syllabic competition might be preferentially words sharing the first syllable and the same number of syllables, as alluded to once in the literature (Perea \& Carreiras, 1998). Analyses of the separate contributions of the number of HFSNA and the number of HFSNS in hierarchical regressions on reaction times of Experiments 1 and 2 confirmed that the number of HFSNS contributed to latencies, $F(1,55)=2.71, p=.009($ Exp. 1),

Table 4 Pearson product-moment $(r)$ and partial (pr) correlations between the reaction times in Experiments 1 and 2 and three predictors

\begin{tabular}{llll}
\hline & Predictors & $r$ & $\mathrm{pr}$ \\
\hline Experiment 1 & (1) Lexical frequency (log) & -.23 & $-.26^{*}$ \\
& (2) Number of HFSNS & .39 & $.34^{* *}$ \\
& (3) Number of HFSNA & .20 & .17 \\
Experiment 2 & (1) Lexical frequency (log) & -.26 & $-.28^{*}$ \\
& (2) Number of HFSNS & .31 & $.28^{*}$ \\
& (3) Number of HFSNA & .14 & .12
\end{tabular}

Numbers in parentheses $(1,2,3)$ indicate the order of entry into hierarchical regression analyses and $F(1,53)=2.16, p=.035$ (Exp. 2), contrary to the number of HFSNA, $F(1,55)=1.26, p=.21($ Exp. 1), and $F<1$ (Exp. 2) (see Table 4).

At a theoretical level, this suggests that the cohort of competitors activated during lexical access in visual word recognition is smaller than previously thought. A bisyllabic word in French has on average 87 syllabic neighbours of higher frequency when the computation is performed, whatever the syllabic length. Not all of the representations of these words may compete during written word processing, but rather the word representations most similar to the target words - that is, those sharing an identical number of syllables in addition to the same first syllable (e.g., 30 words out of the 87 syllabic neighbours for bisyllabic target words). This suggests that cohorts of syllabic competitors could get narrower on the basis of the number of syllables.

One could argue that this conclusion is inconsistent with recent studies on orthographic neighbourhood showing that orthographically similar words mismatched for letter length (e.g., derive/drive, widow/window) are potential competitors during written word recognition (e.g., Davis et al., 2009; Yarkoni et al., 2008). According to us, this discrepancy underlines the limits of comparisons between orthographic neighbours (a high percentage of letters in common) and syllabic neighbours (only one syllable in common). Words have many more syllabic than orthographic neighbours, and it seems very unlikely that all of these HFSNs would have a direct inhibitory influence on word processing, as suggested by our data. Additionally, stating that syllabic competitors share the same number of syllables does not imply that they share the same number of letters (e.g., café, caler, canard). From a phonological perspective, the difference between effects of syllabic neighbourhood and those reported with orthographic neighbours from the addition or deletion of letters could be explained by the different statuses of letters and syllables. Given that a single letter does not systematically code for a phoneme, competition between lexical representations at a phonological level necessarily involves words of different letter lengths, and thus requires some flexibility during processing of letter number in written words. Concerning syllables, given that syllabic representations that are activated during visual word recognition are supposed to be phonological in nature, their activation could be triggered by letter groups of different lengths (e.g., both $f_{o}$ and fau are assumed to activate /fo/; see, e.g., Carreiras, Ferrand, Grainger, \& Perea, 2005). In that case, syllabic length would remain a reliable basic phonological feature to discard lexical representations as potential candidates. ${ }^{3}$ This proposal is consistent with studies on syllabic length showing that the number of syllables in

\footnotetext{
${ }^{3}$ We thank Markus Conrad for this suggestion.
} 
polysyllabic words is encoded early, at a prelexical level (e.g., Ferrand \& New, 2003).

On the other hand, though an effect of HFSN number was found when this number was computed from words of similar length (here, two syllables), but not when computed from polysyllabic words of any length (potentially from two to eight syllables), it remains possible that the effect of HFSN number could decrease gradually as a function of syllable number gap (i.e., bisyllabic words would be stronger competitors than trisyllabic ones, which themselves would be stronger than quadrisyllabic ones, and so on). Actually, this theory would be in line with data on orthographic neighbourhood showing that the higher the letter gap between neighbours, the weaker the influence of these neighbours (see Welvaert, Farioli, \& Grainger, 2008). One way to account for this potential decrease of activation as a function of syllabic length is to assume a lengthsensitive mechanism, as implemented in interactive activation-based models, that would constrain the activation of the potential competitor pool (Smith, Jordan, \& Sharma, 1991). In that case, letter strings would be syllabically parsed in early stages so that both syllable-based units and syllabic length could be extracted. Lexical representations sharing the first syllable with the input word and having the closest number of syllables would be the most activated, as well as the most involved in the following competition process at a lexical level. This length-sensitive mechanism would therefore be flexible, and lexical representations would be weighted continuously and gradually, according to the similarity between their syllabic length and that of the written word to be identified (see also Davis et al., 2009).

To conclude, the present study showed that all of the words sharing a given first syllable with a target word (referred to as syllabic neighbours up to now) do not have the same weight in the process of lexical competition mediated by syllabic representations: Those also sharing their total number of syllables with the target inhibit target processing most strongly.

Author note We thank two anonymous reviewers and Markus Conrad for helpful comments on an earlier version of the manuscript.

\section{References}

Álvarez, C. J., Carreiras, M., \& de Vega, M. (2000). Syllablefrequency effect in visual word recognition: Evidence of sequential-type processing. Psicológica, 21, 341-374.

Álvarez, C. J., Carreiras, M., \& Taft, M. (2001). Syllables and morphemes: Contrasting frequency effects in Spanish. Journal of Experimental Psychology. Learning, Memory, and Cognition, 27, 545-555. doi:10.1037//0278-7393.27.2.545

Carreiras, M., Álvarez, C. J., \& de Vega, M. (1993). Syllable frequency and visual word recognition in Spanish. Journal of Memory and Language, 32, 766-780. doi:10.1006/jmla.1993.1038
Carreiras, M., Ferrand, L., Grainger, J., \& Perea, M. (2005). Sequential effects of phonological priming in visual word recognition. Psychological Science, 16, 585-589. doi:10.1111/ j.1467-9280.2006.01821.x

Carreiras, M., \& Perea, M. (2002). Masked priming effects with syllabic neighbors in a lexical decision task. Journal of Experimental Psychology. Human Perception and Performance, 28, 1228-1242. doi:10.1037/0096-1523.28.5.1228

Chetail, F., \& Mathey, S. (2009). The syllable frequency effect in visual recognition of French words: A study in skilled and beginning readers. Reading and Writing, 22, 955-973. doi:10.1007/s11145-008-9135-9

Coltheart, M., Davelaar, E., Jonasson, J. T., \& Besner, D. (1977). Access to the internal lexicon. In S. Dornic (Ed.), Attention and performance VI (pp. 535-555). Hillsdale: Academic Press.

Conrad, M., Carreiras, M., \& Jacobs, A. M. (2008). Contrasting effects of token and type syllable frequency in lexical decision. Language and Cognitive Processes, 23, 296-326. doi:10.1080/ 01690960701571570

Conrad, M., Carreiras, M., Tamm, S., \& Jacobs, A. M. (2009). Syllables and bigrams: Orthographic redundancy and syllabic units affect visual word recognition at different processing levels. Journal of Experimental Psychology. Human Perception and Performance, 35, 461-479. doi:10.1037/ a 0013480

Conrad, M., Grainger, J., \& Jacobs, A. M. (2007). Phonology as the source of syllable frequency effects in visual word recognition: Evidence from French. Memory and Cognition, 35, 974-983. doi:10.3758/BF03193470

Conrad, M., \& Jacobs, A. M. (2004). Replicating syllable frequency effects in Spanish in German: One more challenge to computational models of visual word recognition. Language and Cognitive Processes, 19, 369-390. doi:10.1080/ 01690960344000224

Conrad, M., Tamm, S., Carreiras, M., \& Jacobs, A. M. (2010). Simulating syllable frequency effects within an interactive activation framework. European Journal of Cognitive Psychology, 22, 861-893. doi:10.1080/09541440903356777

Davis, C. J., Perea, M., \& Acha, J. (2009). Re(de)fining the orthographic neighbourhood: The role of addition and deletion neighbours in lexical decision and reading. Journal of Experimental Psychology. Human Perception and Performance, 35, 1550-1570. doi:10.1037/a0014253

Ferrand, L., \& New, B. (2003). Syllabic length effects in visual word recognition and naming. Acta Psychologica, 113, 167-183. doi:10.1016/S0001-6918(03)00031-3

Forster, K. I., \& Forster, J. C. (2003). DMDX: A Windows display program with millisecond accuracy. Behavior Research Methods, Instruments, \& Computers, 35, 116-124. doi:10.3758/ BF03195503

Jaeger, T. F. (2008). Categorical data analysis: Away from ANOVAs (transformation or not) and towards logit mixed models. Journal of Memory and Language, 59, 434-446. doi:10.1016/j. jml.2007.11.007

Mathey, S., \& Zagar, D. (2002). Lexical similarity in visual word recognition: The effect of syllabic neighbourhood in French. Current Psychology Letters, 8, 107-121.

Mathey, S., Zagar, D., Doignon, N., \& Seigneuric, A. (2006). The nature of syllabic neighbourhood in French. Acta Psychologica, 123, 372-393. doi:10.1016/j.actpsy.2006.02.003

McClelland, J. L., \& Rumelhart, D. E. (1981). An interactive activation model of context effects in letter perception: Part 1 . An account of basic findings. Psychological Review, 88, 375407. doi:10.1037/0033-295X.88.5.375

New, B., Pallier, C., Brysbaert, M., \& Ferrand, L. (2004). Lexique 2: A new French lexical database. Behavior Research 
Methods, Instruments, \& Computers, 36, 516-524. doi:10.3758/ BF03195598

Perea, M., \& Carreiras, M. (1998). Effects of syllable frequency and syllable neighbourhood frequency in visual word recognition. Journal of Experimental Psychology. Human Perception and Performance, 24, 134-144. doi:10.1037/0096-1523. 24.1.134

Perea, M., Rosa, E., \& Gómez, C. (2002). Is the go/no-go lexical decision task an alternative to the yes/no lexical decision task? Memory and Cognition, 30, 34-45. doi:10.3758/ BF03195263

Smith, P. T., Jordan, T. R., \& Sharma, D. (1991). A connectionist model of visual-word recognition that accounts for interactions between mask size and word length. Psychological Research, 53, 80-87. doi:10.1007/BF00867335

Stenneken, P., Conrad, M., Hutzler, F., Braun, M., \& Jacobs, A. M. (2005). Frequency effects with visual words and syllables in dyslexic reader. Behavioural Neurology, 16, 103117.

Welvaert, M., Farioli, F., \& Grainger, J. (2008). Graded effects of number of inserted letters in superset priming. Experimental Psychology, 55, 54-63. doi:10.1027/1618-3169.55.1.54

Yarkoni, T., Balota, D., \& Yap, M. (2008). Moving beyond Coltheart's $N$ : A new measure of orthographic similarity. Psychonomic Bulletin \& Review, 15, 971-979. doi:10.3738/ PBR.15.5.971 